\title{
HEAT TRANSFER CHARACTERISTICS OF SWIRLING IMPINGING JETS
}

\author{
Karl J. Brown ${ }^{1}$, Tim Persoons, Darina B. Murray \\ Department of Mechanical Engineering, Parsons Building, \\ Trinity College, Dublin 2, Ireland
}

\begin{abstract}
Impinging jets are well renowned for their abilities to achieve significantly high heat transfer coefficients. It has been found in previous studies that the incorporation of a swirl in the flow can enhance heat transfer but it can also decrease it. The objective of this research is to discover the defining characteristics of swirling impinging jets and to find an optimal swirl geometry for enhancing the heat transfer of the system. Using thermal imaging and hot film sensor techniques the heat transfer distribution of the swirling jet is examined in the context of the flow field; heat flux fluctuations at the impinging surface are investigated also.
\end{abstract}

Keywords: Heat transfer swirling impinging jet fluctuations.

\section{INTRODUCTION}

Impinging jets are widely used in industrial cooling applications due to their well established abilities to develop high heat and mass transfer. Examples of such applications include glass tempering, turbine blade cooling and thermal control of high power electronic systems.

Impinging jets can be used in a range of different scenarios due to their versatility. For example in those situations which require a large surface area to be covered, arrays of jets can be used and the flow rate of the fluid through the jet nozzle and the height of the nozzle above the impinging surface adjusted for a specified desired effect. A degree of swirl may also be incorporated into the flow to enhance the cooling effect further.

Jet impingement cooling has been looked at in some detail over the years, spanning different methods for examining the flow under such scenarios as single jets, jet arrays, synthetic jets and swirling jets. With regard to single circular impinging jets, a review by Jambunathan et al. [1] examined several aspects resulting from nozzle geometries such as long pipes, contoured nozzles and orifice plates. This discussion addressed aspects such as the length of the potential core and explanations for secondary and tertiary peaks and the effect of nozzle geometry. In a paper presented by Bakirci and Bilen [2], the effects of inducing swirl in a straight pipe jet are examined. In order to generate swirl special inserts were designed to be placed inside a straight pipe. The inserts were devised to guide the fluid through four separate channels rotating about the pipe's central axis. Due to the structure of the inserts however, a blockage in the centre caused a reduction in the heat transfer directly below, at the stagnation point.

Similar experiments performed by Lee et al. [3] involved the design of special swirl generating inserts which also lead to a blockage in the exiting fluid flow causing the heat transfer to be greatly diminished within the stagnation point region for low nozzle heights.

Huang and El-Genk [4] took an approach resembling the two previously mentioned. The major difference introduced was that for this study the inserts were placed one diameter from the end of the housing pipe. This allowed for the swirling effect of the flow to develop. This aspect of a separation between the swirl generator and the nozzle exit was also incorporated into the experiments of Alekseenko et al. [5] for analysing the flow using two-dimensional particle image velocimetry,

Numerical models of the effects of imposing swirl on axial and radial jets were discussed by Owsenek et al. [6]. In this study it was observed that the axially swirling jet significantly reduced the heat transfer of the impingement surface for $H / D=1.25$ and for Reynolds numbers below and including 1000. Similarly, Ward and Mahmood [7] found that the induced swirl in the flow reduced the heat transfer considerably. However it was found by Atsushi et al. [8] that a high intensity of swirl in an impinging air jet caused an increase in the radial width of the jet and in the distance of the maximum local heat transfer coefficient from the stagnation point.

Taking into account past investigation of swirl jets and their design, the present study sets out to explore different geometries aimed at providing an enhancement in heat transfer over a non-

\footnotetext{
${ }^{1}$ Corresponding Author : kbrown@tcd.ie
} 
swirling jet. Using thermal imaging techniques along with a system for measuring fluctuating heat transfer the effect of inducing swirl into the jet flow is explored.

\section{EXPERIMENTAL APPROACH}

\section{Experimental Rig and Instrumentation}

Time Averaged Heat Transfer Measurements

The main test facility consists of a nozzle that directs a jet of air at an electrically heated metal foil, whose surface temperature is measured with a thermal imaging camera.

As shown in Figure 1 the experimental rig's frame was designed to house the jet assembly, the impingement surface and the thermal imaging camera. The foil is mounted horizontally, with the jet impinging normal to the upper surface and the thermal camera directed at the lower surface of the foil.

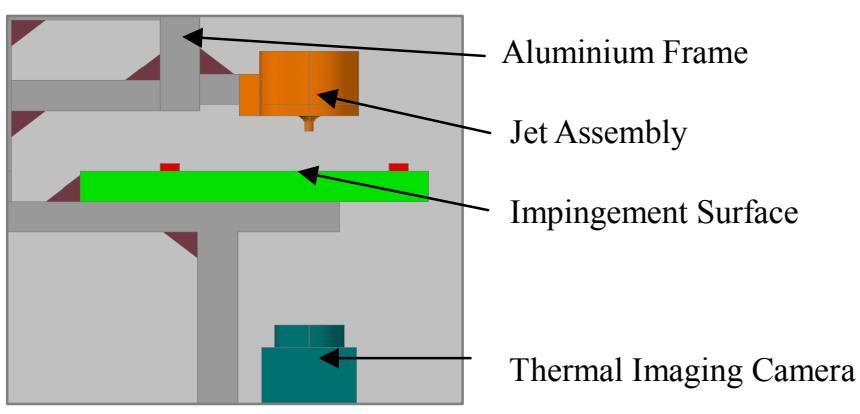

Figure 1: Experimental Rig

The contoured jet assembly shown in Figure 2 was created using a Dimension $^{\mathrm{TM}}$ rapid prototyper from a previously designed setup for jet based projects and was developed with a view to integration onto other experimental rigs for heat transfer fluctuation measurements.

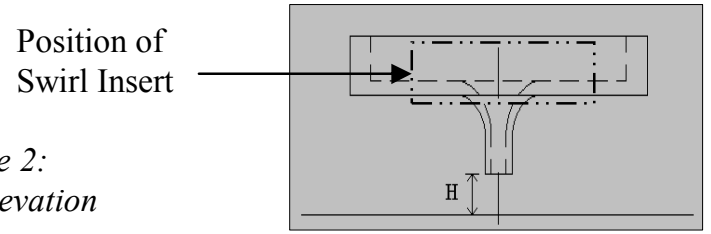

Jet Elevation

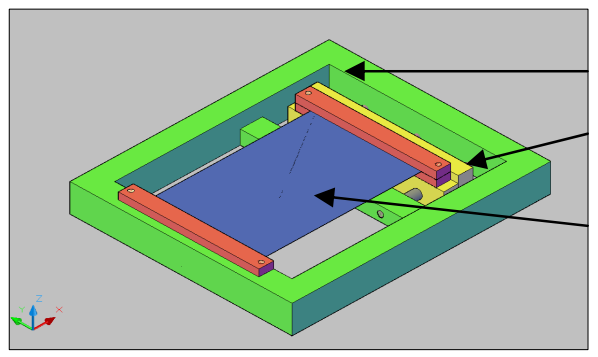

Perspex Mount

Perspex Slider

Foil

Figure 3:

Impingement Surface

The impingement surface, Figure 3, consists of a stainless steel foil, with an area of $150 \times 190 \mathrm{~mm}^{2}$ and a thickness of $25 \mu \mathrm{m}$, clamped between two copper bus bars at each end. The impingement surface mount is made of Perspex and includes an internal movable section on three linear sliding bearings.

One end of the foil is attached to the movable section (yellow section in image) and the other end to the main outer clamp section (green section in image). Using springs with each of the slider bearings, the foil is kept taut at all times during testing.

The foil is connected at either end to an AC to DC power supply, Lambda GEN6-200, which provides a specified amount of current to the foil. The current from the power supply, along with the foil resistance, determines the heat flux generation of the foil. The temperature of the foil is then a result of the generated heat flux in balance with the losses to convection, radiation and conduction to the ambient air.

The circular jet, with a nozzle diameter of $5 \mathrm{~mm}$, is positioned above and aimed at the centre of the stainless steel foil, the underside of which is coated in matt back paint. A thermal imaging camera [FLIR Systems ${ }^{\mathrm{TM}}$ Thermovision $^{\mathrm{TM}}$ A40] is then positioned underneath the foil, axisymmetric to the jet.

Different jet inserts were designed to be attached to the jet in order to generate swirl in the flow. The inserts were created to apply a distinct angular swirl motion while not causing a blockage area in the centre, as appeared in past experimentation such as those from Bakirci and Bilen [2] and Lee et al. [3] where the swirl generators divided the flow into four separate streams. The generators used for this project allowed the streams to rejoin and a continuous flow emerge from the nozzle, similar to those used by Huang and El-Genk [4] and Alekseenko et al. [5].

By retaining a constant flow rate through the jet nozzle, using an Omega FMA-1600 flowmeter, a steady stream of air impinges onto the surface of the foil. The temperature of the cooled foil is recorded using the thermal imaging camera. These recordings are acquired with the nozzle set at various heights above the foil and at increasing Reynolds numbers. The resulting thermal images are analysed using a Matlab program written to correct for the effects of natural convection, radiation and lateral conduction, and graphs of local Nusselt numbers are created.

\section{Swirl Design Details}

Two inserts have been designed and tested so far. Swirl $A$ and Swirl $B$ are designed in order to incorporate a rotational aspect to the jet flow.

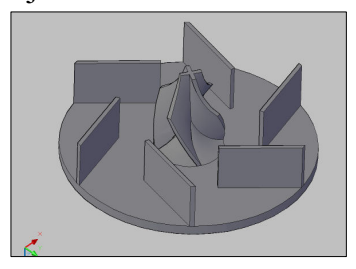

Figure 4:

Insert for Swirl A

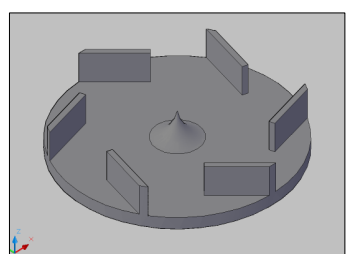

Figure 5:

Insert for Swirl B 
Swirl $A$ has two inclusions in its design; radial guide vanes to direct the flow and a ' + ' cross-section column in the centre, known as the swirl core, which has been twisted axially to obtain a desired angle with the horizontal. For this case the swirl core makes an angle of $45^{\circ}$. The swirl core is designed to pass down into the curved part of the nozzle, shown in Figure 2, until it straightens. This was to ensure that the flow from the four chambers would recombine before being expelled from the exit of the jet.

Swirl $B$ is a scaled down version of Swirl $A$ and without the swirl core. The flow area in this case is a third that of Swirl $A$ which increases the speed passing through the guide vanes threefold, causing the guide vanes to have a larger effect on the swirl of the flow compared to Swirl A.

The swirl numbers corresponding to each design, are calculated according to theory by Gupta et al. [11] and implemented by Alekseenko et al. [5] using the following equation:

$$
S_{n}=\frac{2}{3}\left[\left(1-\left(\frac{r}{R}\right)^{3}\right) /\left(1-\left(\frac{r}{R}\right)^{2}\right)\right] \tan \theta
$$

where $r$ and $R$ are the inner and outer radii of the swirl generator and $\theta$ is the angle of the swirl fins. The resulting swirl numbers, $\mathrm{S}_{\mathrm{n}}$, for Swirl Insert $A$ and Swirl Insert $B$ are 0.67 and 0.22 respectively.

Further swirl designs are to be tested in the future to analyse independantly the effect of the swirl core, the guide vanes and the insert height further.

\section{Data Analysis}

In order to calculate the Nusselt number distribution the following equations were used.

Using images from a thermal camera, the temperature of the foil is extracted over a specific area. Two images are used, representing the adiabatic and surface temperature, $T_{\text {adiabatic }}$ and $T_{\text {surface }}$ respectively, to calculate the film temperature, $T_{\text {film }}$, which is in turn used to determine the air properties to be used in the corresponding equations. The equation:

$$
q_{\text {conv, }}=h \cdot\left(T_{\text {surface }}-T_{\text {adiabatic }}\right)
$$

is then used to estimate the value of the heat transfer coefficient, $h$.

Having calculated the heat transfer coefficient, the Nusselt number, $N u$, is determined from:

$$
N u_{D}=\frac{h \cdot D}{k}
$$

Each test is performed at a specified Reynolds number which is estimated using:

$\operatorname{Re}_{D}=\frac{\rho U D}{\mu}$

where $\rho$ is the density of air; $\mu$ is the viscosity of air; $v$ is the kinematic viscosity of air; $U$ is the velocity and $D$ is the nozzle diameter; $A$ is the nozzle area.

To measure losses in heat from the surface to the surroundings the effects from natural convection and radiation, as well as lateral conduction, are taken into account.

The following equation describes the energy balance of the system.

$$
q_{\text {conv }}^{\prime \prime}=q^{\prime \prime} \text { gen }^{-q^{\prime \prime}} \text { conver }{ }^{-q "}{ }^{\prime \prime} \text { rad, upper }{ }^{-q} \text { rad, lower }{ }^{+q^{\prime \prime}} \text { lc }
$$

Natural convection heat loss from the underside of foil is estimated from:

$$
q_{\text {conv, }}{ }_{\text {lower }}=\frac{C \cdot(G r \cdot \operatorname{Pr})^{m} \cdot k \cdot\left(T_{\text {surface }}-T_{\text {adiabatic }}\right)}{L}
$$

where $C$ and $m$ are constants depending on the Rayleigh number and boundary conditions of the system outlined by Holman [9].

The radiative heat loss is estimated from:

$q_{\text {rad }}^{\prime \prime}=\varepsilon \cdot \sigma \cdot\left(T_{\text {surface }}^{4}-T_{\text {adiabatic }}^{4}\right)$

and the lateral conduction term can be quantified by Geers et al. [10] as:

$$
q^{\prime \prime}{ }_{l c}=k . t .\left(\frac{\delta^{2} T_{\text {surface }}(x, y)}{\delta x^{2}}+\frac{\delta^{2} T_{\text {surface }}(x, y)}{\delta y^{2}}\right)
$$

\section{Fluctuating Heat Transfer Measurements}

The experimental apparatus used to quantify the heat transfer fluctuations for each of the swirl geometries is a test facility used in previous research on oblique, swirling and synthetic impinging jets, described by O'Donovan et al. [12]. The rig involves a copper plate maintained at a uniform wall temperature which contains an $\mathrm{RdF}{ }^{\circledR}$ Micro-Foil and a Senflex ${ }^{\circledR}$ Hot Film Sensor flush with the surface over which the jet passes. The plate is motorized to move across the field of impingement. The plate is heated from underneath using a heating pad connected to a variable power supply in order to control its temperature. A flow controller was used to manage the flow rate of the air exiting the jet nozzle. This is shown in Figure 6. 


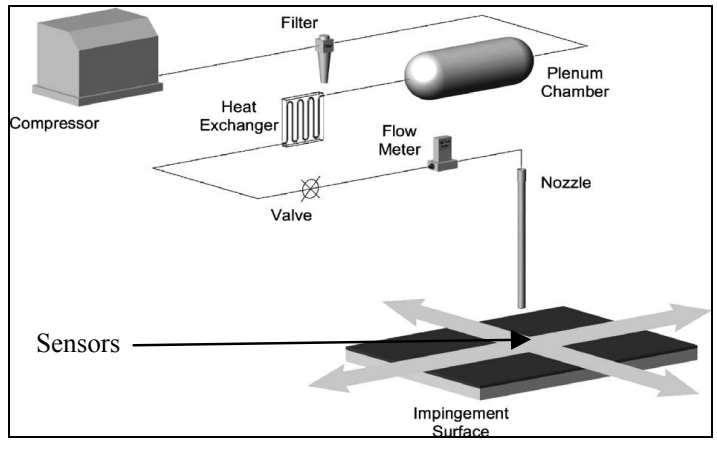

Figure 6: Experimental Setup for Fluctuating Heat Transfer Measurements [13]

The entire device is controlled via a LabVIEW ${ }^{\mathrm{TM}}$ program that records nozzle diameter and fluid flow rate and drives the plate so that the sensor passes beneath the nozzle while recording data as defined by the user. At the end of the test the program outputs the data required to analyse the heat transfer due to the jet. This data includes position, flow rate, temperatures of the jet, the surrounding air, the micro-foil and the hot film, along with the respective voltages produced by the micro-foil and hot film sensors which relate to specific calibrated heat flux measurements.

The fluctuating heat transfer is represented by $N u$, the fluctuating Nusselt number. This is calculated using the fluctuating component of the heat flux measured by the hot film sensor, q'. Details of this calculation are explained within O'Donovan [14]. Although the fluctuating heat transfer measurements are obtained for an isothermal rather than uniform wall flux thermal boundary condition, the measurement setup did not permit such measurements to be obtained for the uniform wall flux case used for time averaged tests. Nevertheless, it is believed that the fluctuating heat transfer profiles can provide qualitative information towards identifying swirl induced heat transfer mechanisms.

\section{Experimental Procedure}

Time Averaged Heat Transfer Measurements

Before tests began the air supply was activated and a steady flow was established corresponding to the Reynolds number required. Once the flow has stabilised a series of images are taken by the thermal camera of the foil and are displayed using ThermaCAM Researcher Pro 2.8 SR-1. Due to past experimentation it has been found that thirty images at a rate of 60 images/second are sufficient to have an accurate representation of the surface temperature. These images are later averaged and filtered to give a single image of the temperature distribution of the foil which is then used to calculate the temperature difference between a heated and an unheated foil.
Figure 7:

Foil as seen by thermal imaging camera during cooling

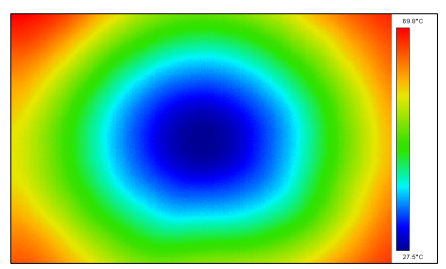

Once an initial adiabatic test has been performed on the foil the power supply is turned on and specific current levels are used to heat the foil. The heated foil temperature is then allowed to stabilise under the jet for several minutes before a test is recorded. These tests also acquire thirty images as with the adiabatic test and are subsequently averaged using Matlab. A typical image is shown in Figure 7. This Matlab code takes both of these averaged images and, after filtering the images, compares each cell, which contains the temperature of the foil at that point, in order to calculate the heat transfer coefficient, $h$, from the power input and the local temperature difference. The effects of heat loss from the system through natural convection, radiation and lateral conduction are also taken into account and the Nusselt number is then calculated as described in the previous section.

The images themselves are $320 \times 240$ cells in size, so at the jet stagnation point coordinate, $[160,120]$, the Nusselt number was averaged radially and the result graphed as $N u v s$. $r / D$ where $r$ is the radius from the centre of the jet and $D$ is the diameter of the jet.

This procedure is carried out for three swirl geometries; No Swirl and Swirl $A$ and $B$ corresponding to the geometries shown in Figures 4 and 5 respectively. To compare the effect of these scenarios the height, $H$, of the nozzle was adjusted to $0.5,1,2,4$, 6, 8 and 10 diameters, $D$, above the impingement surface and flows corresponding to Reynolds numbers, Re, from 8000 to 20000 were examined.

\section{Experimental Uncertainty}

The 95 percent confidence uncertainty of the instrumentation used for testing was estimated for the worst case scenario percentage error. The values were calculated using known techniques outlined by Moffat [15] and are shown in the following table.

\begin{tabular}{|c|c|c|}
\hline Measurement & Units & Uncertainty \% \\
\hline$Q$ & $\mathrm{~m}^{2} / \mathrm{s}$ & 2 \\
\hline$q_{\text {gen }}{ }^{\prime}$ & $W / m^{2}$ & 3 \\
\hline$R e$ & - & 3.5 \\
\hline$T$ & $K$ & 6 \\
\hline$h$ & $W / m^{2} K$ & 12 \\
\hline$N u$ & - & 12.5 \\
\hline$N u^{\prime}[14]$ & - & 30.05 \\
\hline
\end{tabular}

Table 1: Evaluation of Experimental Uncertainty 
Fluctuating Heat Transfer Measurements

The system shown in Figure 6 was setup up to measure the heat transfer fluctuations for each of the three swirl geometries for Reynolds numbers of 8000,14000 and 20000 and nozzle heights of $1 D, 4 D$ and $8 D$. The tests were allowed to run over a radial distance equivalent to $10 D$ to line up with the previous heat transfer results. The results recorded are exported to a Matlab program to calculate the heat transfer fluctuations at each jet to plate spacing and Reynolds number.

\section{EXPERIMENTAL RESULTS}

\section{Stagnation Nusselt Number}

No Swirl

Examining the stagnation Nusselt number variation with $H / D$ shows a small increase in $\mathrm{Nu}$ as the height is extended up to between 6 and $8 D$, after which it begins to drop off, Figure 7 . This pattern is thought to be associated with the extent of the potential core of the jet but requires further investigation.

\section{Swirl A}

When comparing the stagnation Nusselt number with the height above the impingement surface, Figure 8 , the result differs from the $N o$ Swirl situation. For all Reynolds number $\mathrm{Nu}_{\text {stag }}$ increases slightly up to $2-3 D$, then decreases.

\section{Swirl B}

When plotting $\mathrm{Nu}_{\text {stag }}$ against H/D, Figure 9, it is seen that for all Reynolds numbers investigated, $\mathrm{Nu}_{\text {stag }}$ decreases from $0.5 \mathrm{D}$ followed by an increase to $\sim 4 D$; this is followed again by a decreasing slope similar to that of Swirl $A$ for $H / D>\sim 2$.

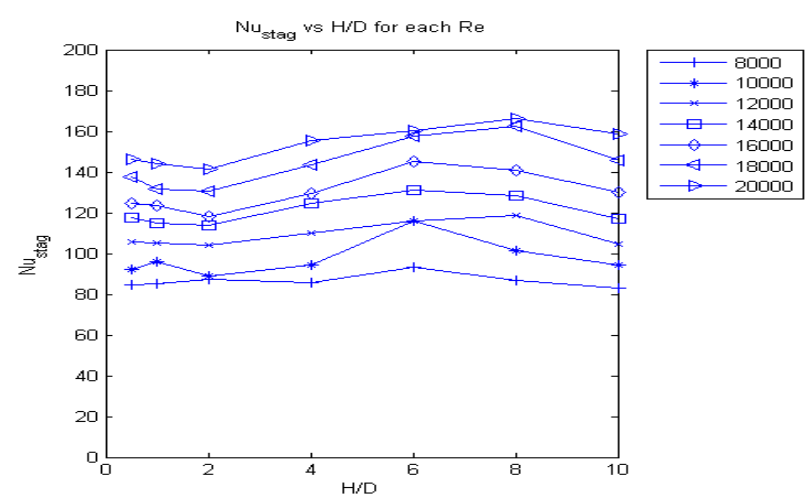

Figure 7: Stagnation Nusselt number distribution for No Swirl

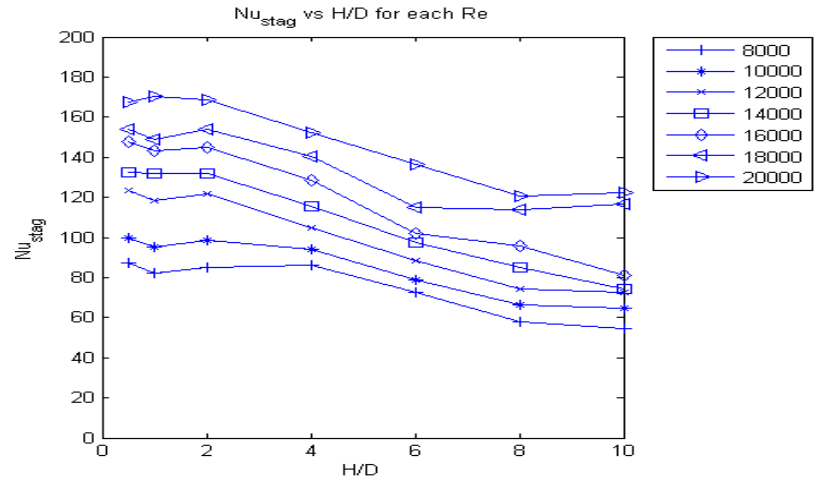

Figure 8: Stagnation Nusselt number distribution for Swirl A

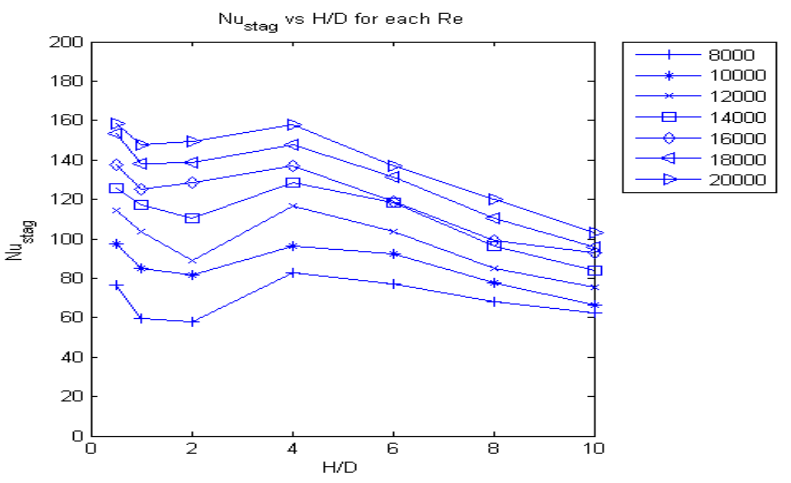

Figure 9: Stagnation Nusselt number distribution for Swirl B

\section{Effect of Swirl}

From examining the stagnation point Nusselt number profiles for the three geometries presented, the influence of the swirl generators is evident.

Comparing the stagnation Nusselt number it was found that, for low $H / D$ and high Reynolds numbers, the swirling jets performed better than the jet with no swirl. For higher heights, $>4 D$, the heat transfer is diminished at the stagnation point for the swirling flow in relation to the non-swirling flow. With regard to the two swirl configurations tested, Swirl $A$ performs better than Swirl B for $H / D$ less than around 4, beyond which point Swirl $B$ begins to perform slightly better. The high stagnation Nusselt numbers found for both swirl flows indicate that the inclusion of a space between the swirl generator and the nozzle exit allows the divided flow to recombine before leaving the nozzle unlike that of Bakirci and Bilen [2] and Lee et al. [3]. 


\section{Time Averaged and Fluctuating Heat Transfer Measurements}

\section{No Swirl}

Time Averaged Heat Transfer Measurements

From analysing the data at each height and Reynolds number similar trends were observed from all tests. It was found that the Nusselt number distribution is at a maximum close to the stagnation point as shown in Figure 10 for a jet to plate spacing of 1 . As the height above the impingement surface is increased this maximum was found to move closer to the stagnation point. For low heights slight secondary peaks can be seen, as evident from Figure 10, but for $H / D>4$ they subside.

From examination of the mean Nusselt number variation with Reynolds number, a steady enhancement occurs as Re increases; this was found to be the case for all $H / D$.

\section{Fluctuating Heat Transfer Measurements}

From the fluctuating Nusselt number profiles, a number of distinguishing factors were noticed. For a $H / D=1$, Figure 11 , and for each of the Reynolds numbers tested the graph shows a very low value at $r / D=0$ up to $\sim 0.5$, after which it begins to increase. This low value of fluctuating Nusselt number is related to the potential core of the flow while the large increases following this region relate to the turbulent mixing in the wall jet.

As the height of the nozzle is increased, the reduction in the fluctuating Nusselt number at the stagnation point becomes weaker due to the thickness of the potential core reducing with distance from the nozzle exit. This effect was seen for all Reynolds numbers and the low heat transfer fluctuations in the stagnation zone disappeared at $H / D=\sim 8$. From this it can be inferred that the length of the potential core is approximately $8 D$ which is consistent with the variation in stagnation Nusselt number with $H / D$ previously discussed.

\section{$\underline{\text { Swirl A }}$}

Time Averaged Heat Transfer Measurements

For low nozzle to plate spacings, as shown in Figure 12, the Swirl $A$ jet develops slight secondary peaks in heat transfer at around an $r / D$ of 2 as with the No Swirl scenario. These were not observed at higher $H / \mathrm{D}$. The maximum point of the Nusselt number distributions is seen to lie within $2.5 \mathrm{~mm}$ of the stagnation point for low heights, as with the No Swirl scenario, but as the height is increased this was found to move out to $5 \mathrm{~mm}$ for low Reynolds numbers. Further investigation is required to understand why this is. The Nusselt number increases steadily as the Reynolds number is increased as it did in the No Swirl situation.

\section{Fluctuating Heat Transfer Measurements}

Unlike the trend seen from the No Swirl at $H / D=1$, there is no zone of low heat transfer fluctuations around the stagnation point for Swirl B. The region appears to be affected by mixing from outside the potential core already, as seen in Figure 13. These high fluctuations are seen at $H / D=4$ and 8 also but have a slow decline from the stagnation point outwards. These results show the effect that the swirl insert may have on the potential core. The length of the core seems to reduce to $\leq 4 D$ which relates well with what was seen in the time-averaged results.

\section{$\underline{\text { Swirl B }}$}

Time Averaged Heat Transfer Measurements

At low $H / D$, specifically below $H / D=6$, the maximum Nusselt number lies at $\sim 3.5 \mathrm{~mm}$ from the stagnation point, an example of which is shown in Figure 14. As the height is then increased to $6 D$ and beyond the maximum Nusselt number is found at the stagnation point. No secondary peaks are observed over the range of tests conducted.

\section{Fluctuating Heat Transfer Measurements}

Similar to Swirl A, Swirl B does not have a region of near-zero fluctuations at the stagnation point for $H / D=1$, Figure 15 , as was found for the plain jet case. The distribution for $H / D=1$ shows a high level of fluctuations near to the stagnation point. These high fluctuations, along with those at the stagnation point not being near-zero, show similarities to the Swirl $A$ distribution which indicated that the end of the potential core of the jet was nearby.

As the height is increased, the inference that the swirl geometry reduces the length of the potential core is reinforced by the measurement of high fluctuations at the stagnation point for $H / D=4$ and for $H / D=8$. This series of results seems to show a reduction of the length of the potential core to $<4 D$. 


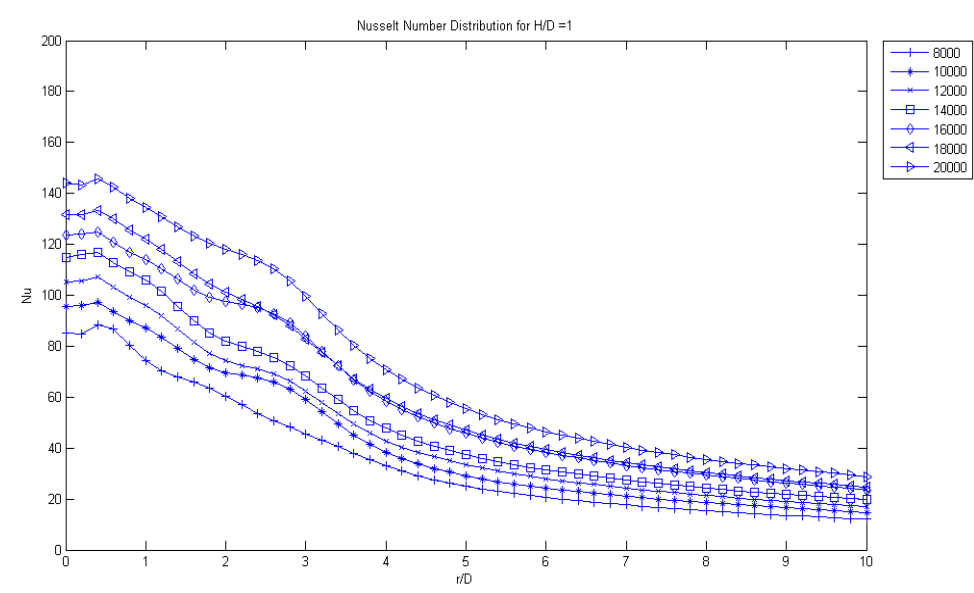

Figure 10: Nu distribution for No Swirl@1H/D

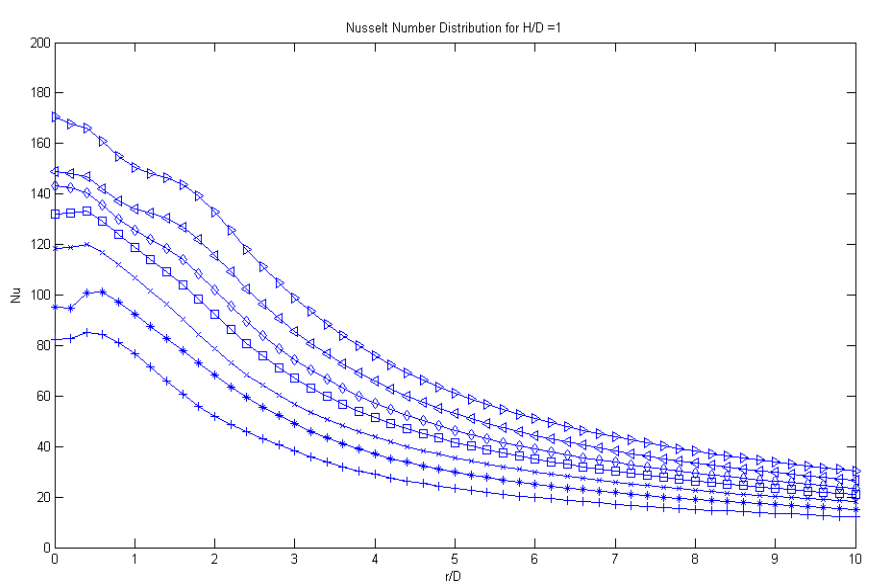

Figure 12: Nu distribution for Swirl A@1H/D

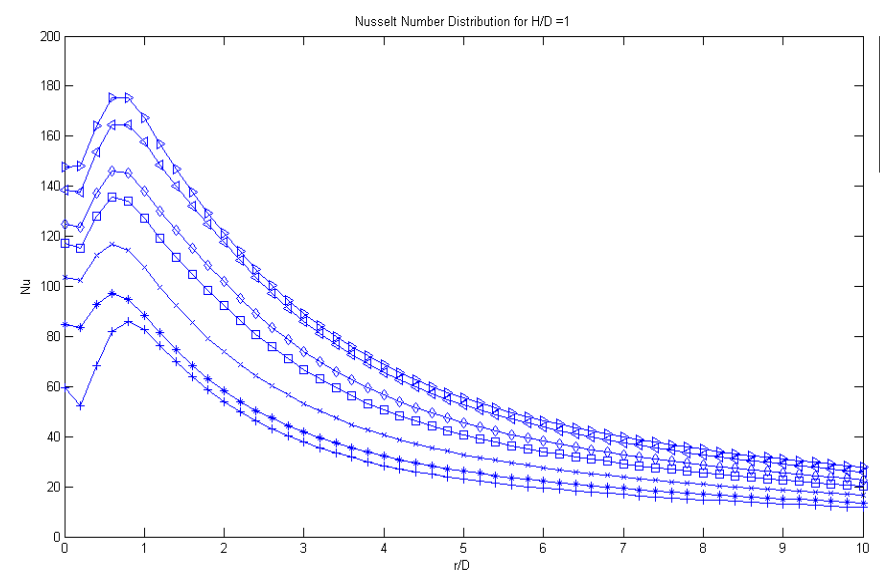

Figure 14: Nu distribution for Swirl B@1H/D

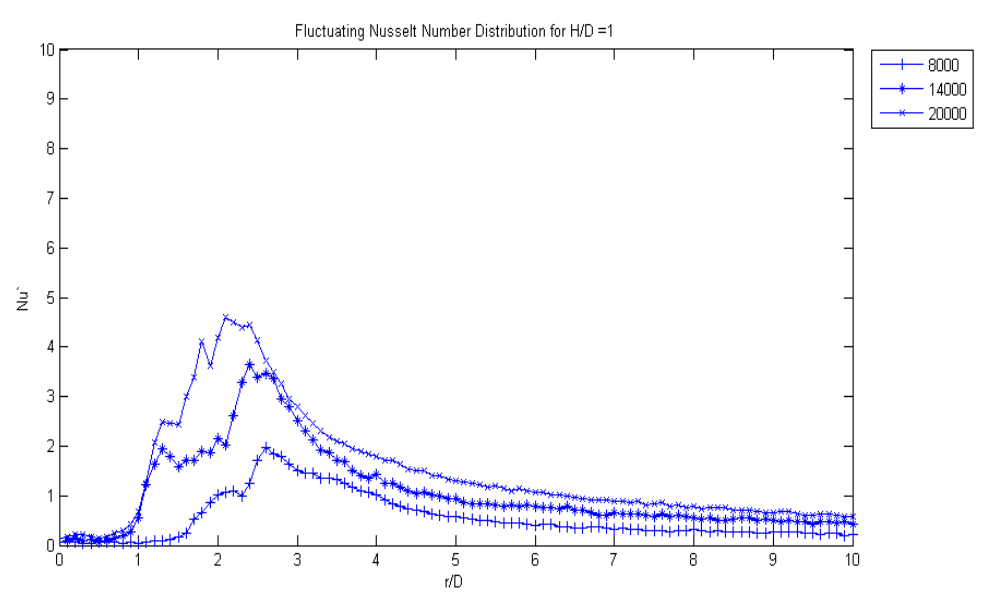

Figure 11: Nu'distribution for No Swirl@1H/D

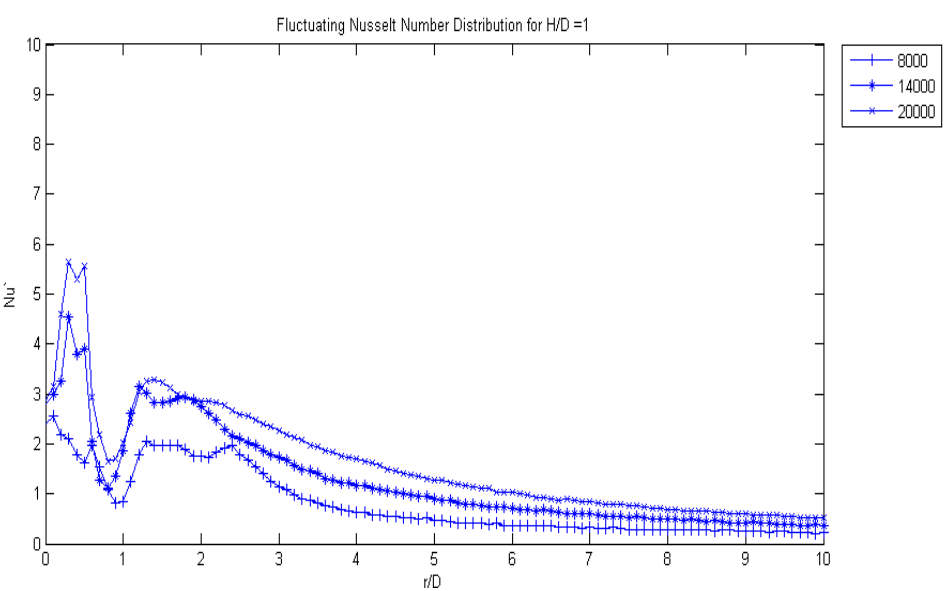

Figure 13: Nu'distribution for Swirl A@1H/D

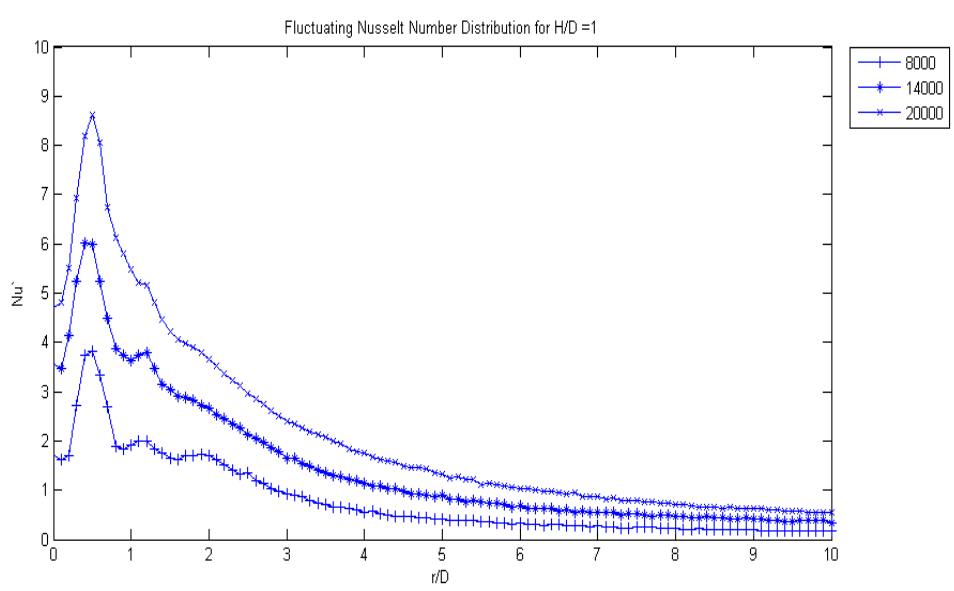

Figure 15: Nu'distribution for Swirl B@1H/D 


\section{CONCLUSIONS}

Fluctuating heat transfer measurements have been conducted alongside time-averaged measurements in an effort to gain insight on the swirl enhanced heat transfer mechanisms in a steady impinging jet.

The results obtained to date indicate that for low jet to surface heights the jets with induced swirl provide higher Nusselt numbers than the jet with no swirl.

Depending on the Reynolds number used, a threshold value was found for the jet to surface spacing beyond which the swirl geometries are ineffective in comparison to that of a jet with no swirl. This value was to be found approximately $3.5 \mathrm{D}$ above the impingement surface.

The maximum value for $\mathrm{Nu}_{\text {stag }}$ for the plain jet case was found to be at a jet spacing of $\sim 6 D$ from the impingement surface. For each of the swirl inserts investigated this value was reduced to $\sim 3-4 D$. These results are consistent with graphs representing the heat transfer fluctuations.

From the results obtained to date, it is unclear why this change occurs but one theory is that the swirl in the flow affects the potential core of the jet causing its length to reduce. Particle Image Velocimetry (PIV) analysis is planned to explore the swirl induced flow field.

\section{ACKNOWLEDGMENTS}

This work was supported by the Irish Research Council for Science, Engineering and Technology "Embark Initiative".

\section{NOMENCLATURE}

$A$ : $\quad$ Impingement surface area

$\left[m^{2}\right]$

$D: \quad$ The diameter of the jet nozzle

$[m]$

The current passing through the foil

$[A]$

$G r$ : Grashof Number

$k$ : The thermal conductivity of air

$[\mathrm{W} / \mathrm{mK}]$

$\mathrm{Nu}$ : $\quad$ Nusselt Number

Pr: $\quad$ Prandtl Number

$q: \quad$ The power applied to the foil

$Q: \quad$ The volume flow rate of air

$r$ : $\quad$ Radial distance

Re : Reynolds Number

$S_{n}: \quad$ Swirl Number

$t: \quad$ Thickness of foil

$T: \quad$ Temperature

$V: \quad$ The voltage across the foil

$x, y: \quad$ Cartesian coordinates across foil

$[W]$

$\left[\mathrm{m}^{3} / \mathrm{s}\right]$

$[m]$

$[m]$

$[K]$

$[V]$

$[m]$

\section{Greek symbols}

$\begin{array}{ll}\varepsilon: & \text { Material Emissivity } \\ \sigma: & \text { Stefan-Boltzmann constant } \\ \mu: & \text { The viscosity of the air } \\ \rho: & \text { The density of the air } \\ v: & \text { The kinematic viscosity of the air }\end{array}$

\section{REFERENCES}

[1] Jambunathan, K., Lai, E., Moss, M., Button, B. (1992) "A review of heat transfer data for single circular jet impingement." Int. J. Heat and Fluid Flow, Vol. 13, No. 2, 106-115

[2] Bakirci, K. and Bilen, K., (2007)

"Visualization of heat transfer for impinging swirl flow." Experimental Thermal and Fluid Science, 32(1): 182-191.

[3] Hee Lee, D., S. Youl Won, Y. Taek Kim and Y. Suk Chung (2002).

"Turbulent heat transfer from a flat surface to a swirling round impinging jet." International Journal of Heat and Mass Transfer 45(1): 223-227.

[4] Huang, L. and El-Genk, M. S., (1998)

"Heat transfer and flow visualization of swirling impinging jets.” Int. J. Heat Transfer, Vol. 41, No. 3, 583-600

[5] Alekseenko, S.V., Bilsky, A. V., Dulin, V. M. and Markovich, D. M. (2007).

"Experimental study of an impinging jet with different swirl rates." International Journal of Heat and Fluid Flow 28 (6): 1340-1359.

[6] Owsenek, B. L., Cziesla, T. N., Mitra, K. and Biswas, G. (1997)

"Numerical investigation of heat transfer in impinging axial and radial jets with superimposed swirl." Int. J. Heat Mass Transfer. Vol 40, No.1, 141-147

[7] Ward, J., and Mahmood, M. (1982)

"Heat transfer from a turbulent, swirling, impinging jet." Proc. $7^{\text {th }}$ Int. Heat Transfer Conference, Vol. 3, 401-407.

[8] Atsushi, N., Yasumitsu, I., Koichi, H. (2003)

"Heat Transfer Mechanism of a Swirling Impinging Jet in a Stagnation Region.” Heat Transfer-Asian Research, 32 (8) 663-673

[9] Holman, J. P., (2002)

"Heat Transfer" International Edition, $9^{\text {th }}$ Edition. McGraw-Hill Publishing

[10] Geers, L. F. G., Tummers, M. J., Bueninck, T. J. and Hanjalic, K. (2008)

"Heat transfer correlation for hexagonal and in-line arrays of impinging jets." Int. J. of Heat and Mass Transfer Vol. 51 (21-22), 5389-5399

[11] Gupta, A.K., Lilley, D.G., Syred, N., (1984) "Swirl Flows." Abacus Press, Kent England.

[12] O'Donovan, T. S. and Murray, D. B. (2008) "Fluctuation fluid flow and heat transfer of an obliquely impinging air jet." Int. J. of Heat and Mass Transfer 51: 6169-6179

[13] O’Donovan, T. S. and Murray, D. B. (2007)

"Jet impingement heat transfer - Part II: A temporal investigation of heat transfer and local fluid velocities." Int. J. of Heat and Mass Transfer 50(17-18): 3302-3314 
[14] O'Donovan, T. S. (2005)

"Fluid flow and heat transfer of an impinging air jet"

Ph.D. Thesis, Department of Mechanical \& Manufacturing Engineering, Trinity College Dublin.

[15] Moffat, R. J. (1988)

"Describing the Uncertainties in Experimental Results." Experimental Thermal and Fluid Science, 1:3-17 